\title{
A geração de resíduos sólidos aeroportuários e suas interfaces com o turismo: o caso do Aeroporto Hugo Cantergiani, Caxias do Sul-RS, Brasil1
}

\author{
Airport solid waste generation and its interfaces with tourism: Hugo \\ Cantergiani Airport's case, Caxias do Sul-RS, Brazil
}

\section{La generación de residuos sólidos aeroportuários y sus interfaces con el turismo: el caso del Aeropuerto Hugo Cantergiani, Caxias do Sul-RS, Brasil}

\author{
Jaciel Gustavo Kunz ${ }^{2}$ \\ Suzana Maria De Conto ${ }^{3}$ \\ Morgana Klipp Demori ${ }^{4}$
}

\begin{abstract}
Resumo: O fenômeno turístico é indissociável dos sistemas de transporte, necessitando ser estudado sob a dimensão ambiental, em especial o modal aéreo. O objetivo desta pesquisa foi investigar a situação da geração de resíduos sólidos no Aeroporto Hugo Cantergiani, situado em Caxias do Sul-RS. A pesquisa, de tipo descritivo-exploratória, envolveu levantamento documental, observação direta e caracterização de resíduos sólidos. Amostrou-se um período de dezoito dias e meio, distribuídos em três semanas/meses em 2012. A movimentação operacional no aeroporto durante a pesquisa foi de 15.543 passageiros. Foram pesados, no período, $878,76 \mathrm{~kg}$ de resíduos, tendo sido segregados e caracterizados $606,83 \mathrm{~kg}$. Desse montante, cerca de $70 \%$ foram oriundos de serviços prestados no sítio aeroportuário e cerca de $30 \%$ provenientes das aeronaves. Verificou-se uma produção por passageiro em aeronaves de 30g/passageiro/viagem e no sítio aeroportuário uma produção per capita de $40 \mathrm{~g} / \mathrm{pessoa} / \mathrm{dia}$. Os componentes mais representativos foram: contaminante biológico (29,54\%), matéria orgânica putrescível (27,16\%), plástico $(19,15 \%)$ e papel e papelão $(14,04 \%)$. Estudos dessa natureza contribuem para o preenchimento de lacunas no conhecimento relacionadas à composição gravimétrica de resíduos sólidos aeroportuários, para a avaliação do impacto ambiental ocasionado pela geração desses resíduos e para o fornecimento de diretrizes voltadas a planos de gestão de resíduos sólidos em aeroportos, infraestruturas de apoio ao turismo.
\end{abstract}

1 Trabalho resultante de dissertação defendida, pelo primeiro autor, no Programa de Pós-graduação em Turismo da Universidade de Caxias do Sul (UCS), tendo sido orientado pela segunda autora. O referido trabalho foi apresentado no X Seminário da Associação Nacional de Pesquisa e Pós-graduação em Turismo (ANPTUR), realizado em 2013 na UCS, Caxias do Sul-RS. Agradecimentos: Aeroporto Hugo Cantergiani de Caxias do Sul-RS e Coordenação de Aperfeiçoamento de Pessoal de Nível Superior (Capes).

2 Bacharel em Turismo pela PUCRS. Mestre em Turismo pela UCS. Docente no Instituto de Ciências Humanas e da Informação (ICHI) da Universidade Federal do Rio Grande (FURG). Membro do Grupo de Pesquisa "Gestão Ambiental no Turismo". E-mail: jacielkunz@furg.br

3 Engenheira Química pela UCS e Doutora em Educação pela UFSCar. Docente no Centro de Ciências Exatas e Tecnologia, no Mestrado em Turismo e no Mestrado Profissional em Engenharia e Ciências Ambientais da UCS. Líder do Grupo de Pesquisa "Gestão Ambiental no Turismo". E-mail: smcmande@ucs.br

4 Acadêmica do Curso de Engenharia Ambiental da UCS. Bolsista de Iniciação Científica. E-mail: morgana.demori@gmail.com 
Palavras-chave: Turismo. Transporte aéreo. Geração de resíduos sólidos aeroportuários. Aeroporto Hugo Cantergiani. Caxias do Sul.

\begin{abstract}
The tourism phenomenon cannot be separated of transport systems and it needs to be examined in the light of the environmental dimension, in particular the air mode. The aim of this research was to investigate the situation of solid waste generation at Hugo Cantergiani Airport, located in Caxias do Sul-RS. The research, which applied a descriptive and exploratory approach, involved document survey, direct observation and solid waste characterization. The period of the sample was of 18 and a half days, spread over three weeks/months in 2012. The operational movimentation at the airport during the conduct of the research was of 15,543 passengers. At the time of the sample $878.76 \mathrm{~kg}$ of waste were weighed of which $606.83 \mathrm{~kg}$ were segregated and characterized. In relation to this amount around $70 \%$ were derived from services undertaken at the airport site and around 30\% came from the aircraft itself. The results revealed that there was a production by passenger at the aircraft of $30 \mathrm{~g} / \mathrm{passenger/trip} \mathrm{and} \mathrm{at} \mathrm{the} \mathrm{airport}$ site a per capita production of 40g/person/day. The most representative components were as follows: biological contaminant (29.54\%), putrescible organic matter (27.16\%), plastic (19.15\%) and paper and paperboard (14.04\%). These types of studies contribute to fill gaps in knowledge related to the gravimetric composition of solid waste in the context of airports, to assess the environmental impacts caused by the generation of such wastes and to provide guidelines for the management plan of solid waste at airports, tourism supporting infrastructures.
\end{abstract}

Keywords: Tourism. Air transport. Airport solid waste generation. Hugo Cantergiani Airport. Caxias do Sul.

Resumen: El fenómeno del turismo es inseparable de los sistemas de transporte y debe ser estudiado en su dimensión ambiental, en particular el transporte aéreo. El objetivo de este trabajo fue investigar la situación de la generación de residuos sólidos en el Aeropuerto Hugo Cantergiani, ubicando en Caxias do Sul-RS. La investigación, descriptiva y exploratória, incluyó el análisis de documentos, la observación directa y caracterización de los residuos. El período de muestreo corresponde a dieciocho días y medio, distribuídos en tres semanas/meses de 2012 . El movimiento operacional del aeropuerto alcanzó el número de 15.543 pasajeros. Durante el muestreo han sido pesados $878,76 \mathrm{~kg}$ de resíduos y han sido separados y caracterizados $606,86 \mathrm{~kg}$. De esta cantidad, en torno de los $70 \%$ han sido generados en el sitio aeroportuário y casi $30 \%$ han sido generados en aeronaves. Los resultados revelaron la producción de $30 \mathrm{~g} /$ pasajero/viaje en aeronaves y la producción de 40g/persona/día en el aeropuerto. Los principales componentes encontrados fueron los suiguientes: contaminante biológico (29,54\%), materia orgánica putrescible (27,16\%), plástico $(19,15 \%)$ y papel y cartón (14,04\%). Este tipo de estudio ayuda a llenar brechas en la producción de conocimiento relacionado a la composición gravimétrica de residuos en el contexto de los aeropuertos, a evaluar los impactos ambientales causados por la generación de estes residuos y a proporcionar orientación a los planes de gestión de residuos en aeropuertos, infraestructuras de apoyo al turismo.

Palavras clave: Turismo. Transporte aéreo. Generación de residuos sólidos en aeropuertos. Caxias do Sul.

\title{
1 INTRODUÇÃO
}

Qual a situação da geração de resíduos sólidos dos aeroportos? Qual a representatividade da geração de resíduos sólidos como aspecto ambiental nos aeroportos? Quais as relações que se estabelecem entre desenvolvimento sustentável, gestão de resíduos sólidos, transportes e turismo?

O turismo vem se apresentando como um fenômeno dos mais destacados na atualidade e perpassa as diversas instâncias da sociedade pós-moderna. O transporte é componente indispensável da vida (pós) moderna, então também o seria para o sistema turístico (Beni, 2007).

$A$ atividade turística se consolida por meio da mobilidade proporcionada pelos sistemas e pelas redes de transporte e, notadamente, o modal aéreo vem a se constituir como um elemento propulsor dessa mobilidade crescente e do desenvolvimento regional. Por outro lado, as atividades e os serviços aeronáuticos e aeroportuários, possibilitadores da expansão dos fluxos 
turísticos, têm sido abordados por meio dos aspectos e impactos ambientais envolvidos, a despeito do otimismo em relação à intensa e crescente utilização do modal aéreo de transporte turístico, sobretudo no Brasil.

Em assim sendo, a atividade de terminais aeroportuários pode apresentar um amplo rol de aspectos ambientais, a começar pela emissão de ruídos e pela considerável geração de resíduos sólidos, entre outros. Logo, tendo em conta o paradigma do desenvolvimento sustentável, cujo desafio, segundo Sachs (2002), é conciliar crescimento econômico, justiça social e preservação ambiental, considera-se a premência de se mitigar os impactos socioambientais dos aeroportos. (Kunz \& De Conto, 2011).

Apesar da relevância e atualidade da temática, por meio de uma pesquisa do tipo estado da arte sobre a produção científica na pós-graduação stricto sensu brasileira, Kunz, De Conto e Denicol (2012), consideram que são escassos os trabalhos que tratam, em termos gerais, sobre gestão e gerenciamento ambiental dos aeroportos. Quando se trata de resíduos sólidos, especificamente, foram localizadas apenas duas dissertações: Hatem (2003) e Schneider (2004).

Nesse sentido, ressalta-se que números ou estimativas referentes aos resíduos sólidos em terminais de transporte e aeroportos são escassos (Schneider, 2004). Em relatório divulgado pelo Instituto de Pesquisas Econômicas Aplicadas (Ipea), Ventura (2012) busca fazer um diagnóstico das condições de gestão de resíduos sólidos de serviços de transporte no Brasil, incluindo os de modal aéreo. As informações prestadas à autora permitiram que fossem apontados os principais entraves nesse quesito, que se voltam, sobretudo, à organização de bancos de dados padronizados e coletados de forma mais abrangente e sistemática.

Ventura (2012) aponta que alguns aeroportos mantêm dados estruturados sobre a geração de resíduos. Outros, de menor movimentação de cargas e pessoas, apresentam pouca informação a esse respeito.

Com a finalidade de suprir essa lacuna teórico-técnica, o objetivo geral deste trabalho é analisar a situação e as condições de geração dos resíduos sólidos no Aeroporto Hugo Cantergiani, situado em Caxias do Sul, no Estado do Rio Grande do Sul. Como objetivos específicos têm-se: a) caracterizar o empreendimento aeroportuário, suas principais atividades e serviços; $b$ ) identificar o movimento operacional de aeronaves e passageiros; c) delimitar setores de geração de resíduos; d) determinar a composição gravimétrica dos resíduos sólidos; e) determinar a produção per capita dos resíduos sólidos; f) avaliar uma possível sazonalidade na geração de resíduos sólidos, tendo como critério a sazonalidade do turismo emissivo e do turismo receptivo de eventos (feira de negócio).

\section{REFERENCIAL TEÓRICO}

Só recentemente é que se reconheceu que o turismo se desenvolve em ambientes que possuem seus próprios limites. Não raro, os limites do desenvolvimento turístico somente são descobertos quando a atividade já gerou danos graves ou irreversíveis por conta da ação de 
gestores turísticos ou dos próprios turistas. (Ayuso, 2002). O "lixo", no contexto das necessárias avaliações de impacto ambiental do turismo, é um indicador a ser devidamente contemplado. (Cooper, Fletcher, Fyall \& Bent, 2007). Peeters, Szimba e Duijnisveld (2007) consideram que um dos entraves de pesquisa dos impactos do turismo a serem superados é a ênfase na avaliação de impactos ambientais nos destinos turísticos, relegando a um plano secundário os impactos decorrentes do deslocamento. Consideram, ainda, que o transporte representa um empecilho na relação turismo e meio ambiente.

Além dos impactos acústicos e atmosféricos do transporte aéreo apontados como sendo os mais proeminentes, existem outros impactos ambientais negativos gerados por aeroportos e suas "zonas industriais", a serem levados em consideração (Blázquez, 2002). Os aeroportos podem ser comparados a pequenas cidades, inclusive de países desenvolvidos. (Blázquez, 2002; Hatem, 2003; Schneider, 2004; Pitt \& Smith, 2003). Isso porque, entre outros fatores, os aeroportos possuem uma grande comunidade aeroportuária, como passageiros, funcionários, acompanhantes e visitantes. Dentro dessas "pequenas cidades" são exercidos atividades e serviços diversos (Schneider, 2004).

Considera-se, desse modo, que por mais integrados socioeconomicamente que os aeroportos estejam com a comunidade do entorno, os aeroportos apresentam alguns "incovenientes", ou externalidades negativas, como, por exemplo, as alterações no meio ambiente ocasionadas pela construção e operação das instalações e serviços no/do aeroporto (solo, fauna, flora, recursos hídricos, prédios históricos, sítios arqueológicos, entre outros). (Palhares, 2000, pp. 30-31).

Atreladas às atividades aeroportuárias e de operação de aeronaves estão numerosos aspectos ambientais ${ }^{5}$ aos quais correspondem impactos ambientais ${ }^{6}$ de diversas ordens e graus. Dentre os aspectos ambientais inerentes à atividade aeroportuária encontra-se a geração de resíduos sólidos. Segundo definição adotada pela Política Nacional de Resíduos Sólidos, estes se referem a todo

\begin{abstract}
Material, substância, objeto ou bem descartado resultante de atividades humanas em sociedade, a cuja destinação final se procede, se propõe proceder ou se está obrigado a proceder, nos estados sólido ou semissólido, bem como gases contidos em recipientes e líquidos cujas particularidades tornem inviável o seu lançamento na rede pública de esgotos ou em corpos d'água, ou exijam para isso soluções técnica ou economicamente inviáveis em face da melhor tecnologia disponível. (Lei n. 12.305, 2010, 2010).
\end{abstract}

5 "Os elementos das atividades, produtos e serviços de uma organização que podem interagir com o meio ambiente são chamados aspectos ambientais. Exemplos incluem lançamentos, emissões, consumo ou reuso de materiais, ou geração de ruído." (ABNT, 2005: 10).

6 "Alterações no meio ambiente, tanto adversas quanto benéficas, que resultem total ou parcialmente de aspectos ambientais, são chamadas impactos ambientais. Exemplos de impactos adversos incluem poluição do ar e a redução de recursos naturais. Exemplos de impactos benéficos incluem melhoria da qualidade do solo ou da água." (ABNT, 2005: 11). 
Já a geração de resíduos sólidos é entendida como a "transformação de material utilizável em resíduo." (ABNT, 1996, p. 2). A geração de resíduos sólidos está diretamente ligada a padrões culturais, à renda e aos hábitos de consumo da sociedade, sendo essas algumas das principais causas da grande quantidade de resíduos, resultado de uma sociedade que pratica, por vezes, consumo desmedido. (Schneider, 2004).

Como categorias de poluição atribuídas à geração e ao descarte dos resíduos e ao seu manejo e à sua disposição inadequados, Lima (2002) aponta a contaminação do solo, do ar e dos recursos hídricos, tanto superficiais quanto subterrâneos. Aponta, ainda, a relação existente entre resíduos e a proliferação de vetores como fator a ser observado. Logo, a fim de minimizar impactos ambientais atrelados às atividades produtivas, a implantação de sistemas de gestão ambiental nas organizações torna-se, pois, necessária. Há que se inserir, nesses sistemas, programas específicos, entre eles, o de resíduos sólidos, que contam com um gerenciamento próprio.

Aliado a isso, há que se destacar que "na gestão e gerenciamento7 de resíduos sólidos, deve ser observada a seguinte ordem de prioridade: não geração, redução, reutilização, reciclagem, tratamento dos resíduos sólidos e disposição final ambientalmente adequada dos rejeitos". (Lei n. 12.305, 2010).

Reconhecendo a especificidade dos resíduos sólidos - e sua geração - nos serviços de transporte, incluindo os aeroportos, é importante apresentar a classificação desses resíduos quanto a sua origem, conforme a Política Nacional de Resíduos Sólidos: "resíduos de serviços de transportes: os originários de portos, aeroportos, terminais alfandegários, rodoviários e ferroviários e passagens de fronteira." (Lei n. 12.305, 2010).

Reconhece-se, além disso, que os aeroportos geram resíduos sólidos em quantidade relevante. (Atkin, Hershkowit \& Hoover, 2006; Gonçalves, 2009; Schneider, 2004). Conforme divulgado por Ventura (2012), o Aeroporto Internacional do Rio de Janeiro, por exemplo, apresentou uma geração de $415.166 \mathrm{~kg}$ mensais. Schneider (2004), por sua vez, constatou, a partir de pesquisa no Aeroporto Internacional de Porto Alegre, que os resíduos gerados pelo serviço de transporte aéreo de passageiros constituem-se basicamente de material de higiene, de asseio pessoal e restos de alimentos, os quais podem veicular doenças provenientes de outros territórios.

Dada essa característica, os resíduos aeroportuários são potencialmente perigosos do ponto de vista de sua patogenicidade, nos termos da Política Nacional de Resíduos Sólidos (Brasil, 2010). Schneider (2004), Pitt e Smith (2003), além de Atkin, Hershkowit e Hoover (2006),

\footnotetext{
"gerenciamento de resíduos sólidos: conjunto de ações exercidas, direta ou indiretamente, nas etapas de coleta, transporte, transbordo, tratamento e destinação final ambientalmente adequada dos resíduos sólidos e disposição final ambientalmente adequada dos rejeitos, de acordo com plano municipal de gestão integrada de resíduos sólidos ou com plano de gerenciamento de resíduos sólidos [...] gestão integrada de resíduos sólidos: conjunto de ações voltadas para a busca de soluções para os resíduos sólidos, de forma a considerar as dimensões política, econômica, ambiental, cultural e social, com controle social e sob a premissa do desenvolvimento sustentável." (Lei n. 12.305, 2010).
} 
consideram que parte dos resíduos gerados é reciclável ou compostável. Mediante estudo realizado por Hatem (2003), o qual lançou mão, entre outras técnicas, da determinação da composição gravimétrica dos resíduos gerados em aeroportos metropolitanos de Belo HorizonteMG, constatou-se que no Aeroporto de Confins, a maior fração era de matéria orgânica putrescível $(45,17 \%)$, seguida de outros $(27,18 \%)$, papel $(21,03 \%)$, plástico $(5,79 \%)$ e, por fim, vidro (0,83\%). (Hatem, 2003). O autor (2003) atribui a incidência na geração dos diferentes componentes a fatores como: quadro de pessoal, duração e horário dos voos (chegadas e partidas), distância do centro urbano, incidência de cargas aéreas, entre outros fatores. (Hatem, 2003).

Acrescentar-se-ia que a incidência e/ou utilização de serviços de alimentação nos aeroportos também interferem na composição gravimétrica de resíduos sólidos, sobretudo na fração de matéria orgânica putrescível. Pitt e Smith (2003) estimam que cerca de $60 \%$ do resíduo gerado no âmbito dos aeroportos do Reino Unido provenha das próprias aeronaves, enquanto que a pesquisa realizada por X. D. Li, C. S. Poon, S. C. Lee, S. S. Chunga e F. Luk (2003), verificou que esse número gira entre 45 a 68\%, em um aeroporto como o de Pequim, na China. Já no Aeroporto de Portland, nos Estados Unidos, o percentual de resíduos sólidos produzidos a bordo de aeronaves giraria entre 45 e 50\% (Atkin, Hershkowit \& Hoover, 2006).

X. D. Li et al. (2003) realizaram a caracterização de resíduos sólidos provindos do serviço de bordo de aeronaves, que se dirigiam ao Aeroporto Internacional de Hong Kong, a partir de uma amostra de oito aeronaves de diferentes alcances. Um dos critérios para análise foi o nível do serviço de bordo oferecido nos voos. Na determinação da composição gravimétrica dos resíduos dos serviços de bordo, a predominância de um componente em relação a outro variou, sobretudo, conforme o alcance do voo e o nível de serviço disponível. Porém, em termos gerais, os resíduos alimentares foram preponderantes, havendo destaque também para o papel e o plástico. A referida pesquisa apresenta como resultado a geração de resíduos sólidos de um total de até $500 \mathrm{~kg}$ por aeronave/voo, o que representa uma produção per capita de 0,38kg por passageiro em classe econômica, $1,14 \mathrm{~kg}$ em classe executiva e 2,84kg em primeira classe (X. D. Li et al., 2003). Em 2004, cada passageiro de companhias aéreas norte-americanas descartava cerca 0,580 kg por viagem, o que equivale a um terço da geração diária desses passageiros. (Atkin; Hershkowit; Hoover, 2006).

\section{METODOLOGIA}

O objeto de estudo "Aeroporto Hugo Cantergiani"8 está situado há três quilômetros do centro de Caxias do Sul, cidade localizada há $130 \mathrm{~km}$ da capital do estado do Rio Grande do Sul,

8 Cabe ressaltar que o Aeroporto Hugo Cantergiani faz parte do sistema de aeroportos, objeto de concessão federal ao Estado do Rio Grande do Sul, administrado por intermédio do Departamento Aeroportuário da Secretaria dos Transportes. O Poder Público do município participa da gestão do aeroporto, mediante acordo de gestão, integrando comissão paritária para a administração aeroportuária, responsabilizando-se pela guarda e vigilância do sítio aeroportuário e pela gestão dos recursos humanos ali em serviço. 
Porto Alegre. A cidade está inserida no contexto da macrorregião turística "Serra Gaúcha" e da microrregião turística Uva e Vinho. Caxias do Sul possui uma ampla variedade de atrativos turísticos, ligados, sobretudo, aos segmentos cultural, gastronômico, de aventura, com especial destaque ao segmento de eventos e negócios. São realizadas importantes feiras de negócios, como a Plastech e a Feira de Subcontratação e Inovação Industrial (Mercopar). Não se pode deixar de mencionar a Festa Nacional da Uva, que ocorre desde 1931. Em função dessas características, Caxias do Sul conta com uma oferta turística estruturada em numerosos serviços de alimentação, meios de hospedagem, serviços de receptivo, roteiros turísticos e opções culturais.

O referido aeroporto possui uma pista de pousos e decolagens de $1.940 \mathrm{~m}$ de comprimento e um pátio com capacidade para até cinco aeronaves Boeing 737-700 - aeronaves de grande porte -, sendo que o seu sítio aeroportuário é de 57 hectares. 0 aeroporto fecha para pousos e decolagens, sobretudo por conta da neblina dos meses de inverno. Por vezes, os passageiros são direcionados, via terrestre, para embarque no Aeroporto Internacional Salgado Filho, na capital, Porto Alegre, há $125 \mathrm{~km}$ de distância. O terminal de passageiros possui atualmente $2.400 \mathrm{~m}$ de área construída (foi reformado e ampliado no final de 2011), e uma capacidade de 350 mil passageiros por ano. O aeroporto possui dez concessionários, além de um contrato com empresa terceirizada - a RP AATA -, que efetua serviços de apoio a passageiros, assistência especial, rampa, limpeza e aviação executiva. Cento e vinte pessoas trabalham no aeroporto.

Mediante execução da técnica da observação direta, elencaram-se atividades e serviços prestados no aeroporto, além do pouso, taxiamento e decolagem de aeronaves. Operavam, nos períodos amostrados, voos regulares de duas grandes companhias aéreas nacionais. Os voos que à época partiam do aeroporto de Caxias do Sul tinham por destino o Aeroporto Internacional de Guarulhos (SP), Aeroporto Internacional Afonso Pena (PR), Aeroporto Internacional de Viracopos (SP) e Aeroporto de Congonhas (SP). Esses voos estão previstos para durar entre $1 \mathrm{~h}$ e $2 \mathrm{~h} 40 \mathrm{~min}$. Uma das variáveis proeminentes do estudo são os serviços oferecidos aos passageiros e/ou turistas, tanto no que se refere à infraestrutura aeroportuária quanto às operações de transporte aéreo propriamente ditas.

Tendo partido de uma revisão de literatura, procedimento característico da pesquisa bibliográfica, a pesquisa adquire caráter descritivo-exploratório, de corte quali-quantitativo. Aliado a isso, fez-se uso do método de estudo de caso. Como técnicas de pesquisa, foram realizados levantamento documental de informações estatísticas da movimentação do aeroporto, observação direta não participante quanto aos serviços do aeroporto e as condições de geração e manejo de resíduo, registros fotográficos e trabalho de campo. Este consistiu na segregação e pesagem no sentido de levantar as características de uma amostragem de resíduos sólidos, sob a forma de determinação da composição gravimétrica. 
A caracterização dos resíduos gerados, que pode incluir a definição da tipologia, composição física, química e/ou biológica, bem como as quantidades, é tida como um dos primeiros procedimentos a ser realizado visando à elaboração de um diagnóstico da geração de resíduos. Monteiro et al. (2001) esclarecem que a composição gravimétrica de resíduos, que consiste em uma caracterização física, traduz o percentual de cada componente em relação à massa total da amostra analisada.

Quanto aos critérios de delimitação do recorte temporal da amostragem, os três períodos de amostragem foram marcados, respectivamente, pelas férias escolares (seis dias e meio em julho) e pela ausência de eventos de turismo e de negócios no município (sete dias em agosto) e pela realização de um evento dessa tipologia, a Mercopar (cinco dias em outubro). A primeira etapa de amostragens (julho) consistiu na pesagem dos resíduos, uma vez não foram apresentadas condições técnicas e sanitárias para se realizar tal tarefa nessa etapa, uma vez que resíduos tidos como contaminantes biológicos ${ }^{9}$ e como matéria orgânica putrescível não se encontravam devidamente separados dos resíduos seletivos que seriam, de fato, segregados pela equipe de trabalho de campo.

Os resíduos gerados e devidamente acondicionados em seus setores de geração foram transferidos pelos funcionários do aeroporto para os contêineres localizados no armazenamento provisório conforme a rotina do sistema de limpeza. Posteriormente, os mesmos foram transferidos até um local coberto, cedido pela direção do aeroporto, dentro do próprio sítio aeroportuário (garagem de um veículo). No local, os resíduos eram segregados segundo categorias de resíduos previamente definidas a partir de Mandelli (1997), Mandelli, Zattera, Carvalho e Matté (2002), De Conto, Silva e Pessin (2005) e De Conto, Pessin, Pistorello, Zaro e Poletto (2009).

Posteriormente, os diferentes componentes eram pesados individualmente e os dados da pesagem eram anotados em planilhas de registro segundo os setores de geração "aeronaves" (divididos em companhia A e B) e "sítio aeroportuário".

\section{RESULTADOS E DISCUSSÃO}

Em uma análise preliminar, pode-se considerar que o fator "turismo emissivo de lazer" tende a ser mais decisivo que o fator "turismo receptivo de negócios e eventos" para a movimentação no aeroporto estudado. Foram analisados, ao todo, os resíduos de bordo de 77 voos regulares, sendo 26 da companhia A e 51 da companhia B. A média de movimentação diária foi a seguinte: 895 passageiros/dia durante a etapa de julho, 806 passageiros/dia em agosto e 815 passageiros/dia em outubro.

\footnotetext{
${ }^{9}$ como exemplos de componentes de resíduos sólidos aeroportuários classificados como contaminantes biológicos, citam-se, especialmente, aqueles oriundos de sanitários de aeronaves e terminais, além de fraldários, ou, eventualmente, resíduos de serviços de saúde que operam no local, tais como, papel higiênico, fraldas descartáveis e similares. essa categoria de resíduos e potencialmente perigosa do ponto de vista de sua patogenicidade, ou seja, o seu caráter de transmissor de determinadas doenças.
} 
Assim, a movimentação média no aeroporto foi maior durante o período de férias escolares, que pode impulsionar, entre outros, o turismo de lazer, emissivo e receptivo do que no período de realização de uma grande feira de negócios na cidade. Uma hipótese é que, neste último caso, parte dos participantes do referido evento, que utilizou o modal aéreo, tenha optado pelo Aeroporto Internacional de Porto Alegre, há duas horas de Caxias do Sul.

$\mathrm{Na}$ Tabela 1 constam os números da geração de resíduos sólidos em aeronaves da companhia A e B, bem como no sítio aeroportuário. Consta, além disso, a movimentação relacionada a essa geração e, a partir desses dados, a produção per capita.

Tabela 1 - Geração de resíduos sólidos aeroportuários durante as três amostragens

\begin{tabular}{|c|c|c|c|c|c|c|c|c|c|c|}
\hline \multirow{2}{*}{ PERÍODO } & \multicolumn{2}{|c|}{$\begin{array}{l}\text { COMPANHIA } \\
\text { AÉREA A }\end{array}$} & \multicolumn{2}{|c|}{$\begin{array}{l}\text { COMPANHIA } \\
\text { AÉREA B }\end{array}$} & \multicolumn{2}{|c|}{ AERONAVES } & \multicolumn{2}{|c|}{$\begin{array}{c}\text { SÍTIO } \\
\text { AEROPORTUÁRIO }\end{array}$} & \multicolumn{2}{|c|}{ TOTAL } \\
\hline & $\begin{array}{c}\text { MASSA } \\
(\mathrm{kg})\end{array}$ & $\%$ & $\begin{array}{c}\text { MASSA } \\
(\mathrm{kg})\end{array}$ & $\%$ & $\begin{array}{c}\text { MASSA } \\
(\mathrm{kg})\end{array}$ & $\%$ & $\begin{array}{c}\text { MASSA } \\
(\mathrm{kg})\end{array}$ & $\%$ & $\begin{array}{c}\text { MASSA } \\
\text { (kg) }\end{array}$ & $\%$ \\
\hline 17 a $23 / 7 / 12$ & 41,17 & 46,80 & 46,80 & 53,20 & 87,97 & 32,35 & 183,96 & 67,65 & 271,93 & 100 \\
\hline 18 a $24 / 8 / 12$ & 55,43 & 49,10 & 57,47 & 50,90 & 112,90 & 30,17 & 261,26 & 69,83 & 374,16 & 100 \\
\hline $1^{\circ}$ a $5 / 10 / 12$ & 37,19 & 57,28 & 27,74 & 42,72 & 64,93 & 27,91 & 167,74 & 72,09 & 232,67 & 100 \\
\hline TOTAL & 133,79 & - & 132,01 & - & 265,80 & - & 612,96 & - & 878,76 & 100 \\
\hline Movimentação ${ }^{10}$ & 2.100 & - & 5.458 & - & 7.558 & - & 15.543 & - & - & - \\
\hline $\begin{array}{l}\text { Produção per } \\
\text { capita }^{11}\end{array}$ & 0,06 & - & 0,02 & - & 0,03 & - & 0,04 & - & - & - \\
\hline
\end{tabular}

Fonte: Elaboração própria dos autores (2012)

Em relação aos resíduos sólidos de aeronaves, adota-se o número de desembarques. Já em relação aos resíduos oriundos do sítio aeroportuário, adota-se a movimentação de pessoas. A produção per capita de resíduos sólidos de aeronaves é expressa em $\mathrm{kg} /$ passageiro/viagem. A produção de resíduos provindos do sítio aeroportuário, por sua vez, é expressa em kg/pessoa.

Pode-se observar a preponderância na geração de resíduos sólidos no próprio sítio aeroportuário (em torno de 70\%). A geração de resíduos sólidos, a bordo de aeronaves que operam voos regulares com destino ao aeroporto estudado, foi de, aproximadamente, 30\%, resultado dissonante de boa parte da literatura. Cabe destacar que os estudos divulgados pela escassa literatura foram realizados, em geral, há cerca de dez anos. Durante essa década, houve uma clara disseminação de companhias aéreas de baixo custo, primeiramente nos países mais desenvolvidos e, posteriormente, em países como o Brasil. Os preços em decréscimo têm atraído um crescente número de turistas, que optam pelo modal aéreo, em função da velocidade, comodidade e dos preços competitivos no que se refere ao transporte rodoviário coletivo. A companhia aérea $B$, cuja geração de resíduos a bordo de suas aeronaves foi investigada, possui,

10 Em relação aos resíduos sólidos de aeronaves, adota-se o número de desembarques. Já em relação aos resíduos oriundos do sítio aeroportuário, adota-se a movimentação de pessoas.

11 A produção per capita de resíduos sólidos de aeronaves é expressa em kg/ passageiro/viagem. A produção de resíduos provindos do sítio aeroportuário, por sua vez, é expressa em kg/pessoa, conforme tabelas anteriormente apresentadas. 
assumidamente, esse perfil. Essa companhia procura minimizar a oferta de serviços de bordo, sobretudo de lanches de bordo. Na maior parte dos seus voos, tem como opção somente a venda desses lanches, o que minimiza drasticamente o consumo, o desperdício e a geração de resíduos sólidos.

Em segundo lugar, o aeroporto pesquisado é de pequeno porte em relação aos maiores do País e do mundo, pelo menos em termos de movimentação de aeronaves, cargas e passageiros. Logo, a oferta de serviços aos passageiros é reduzida. Em termos de alimentação, por exemplo, as opções do aeroporto pesquisado resumem-se a um café (estabelecimento que oferece lanches rápidos). Alguns aeroportos brasileiros contam, até mesmo, com cabines para descanso ou pernoite, dentro do próprio terminal. Ou seja, a gama de serviços do aeroporto é proporcional ao porte do empreendimento, o que repercute, entre outros aspectos, na geração de resíduos sólidos. Não se pode olvidar também o fator climático que, aliado à falta de equipamentos "antineblina" mais eficazes, faz com que haja um considerável número de cancelamentos ou redirecionamentos de voos.

Retomando as peculiaridades dos serviços de transporte de passageiros pelas distintas companhias, constata-s e, a partir dos números e percentuais sobre a geração de resíduos expostos na Tabela 1, que a companhia aérea A produziu pouco mais da metade dos resíduos das aeronaves (50,33\%), durante os períodos pesquisados. A companhia B produziu $49,57 \%$ do total. Tal dado está em consonância ao da movimentação de passageiros pelas companhias, registrada durante as amostragens. Apesar de gerar mais da metade dos resíduos de aeronaves, a companhia aérea $A$ movimentou menos da metade do número de passageiros da companhia aérea $B: 2.100$ contra 5.458. Os serviços de bordo diferenciados, oferecidos pela companhia A, como o lanche de bordo em embalagens fracionadas e a possibilidade de se assistir à tevê de bordo, por meio de um fone de ouvido individual e, por vezes, descartado no final do voo, explica essa maior proporção na geração de resíduos sólidos.

Apontam-se, pois, como fatores intervenientes na geração de resíduos sólidos aeroportuários, os que emergiram a partir da coleta, análise e interpretação de dados do aeroporto em estudo: a) tamanho da comunidade aeroportuária; b) área do sítio aeroportuário; c) sazonalidade da atividade turística que se utiliza do modal aéreo; d) condições climáticas, que se referem, entre outros fatores, ao "teto operacional", ou seja, às condições de tempo e climáticas favoráveis para as operações de pouso e decolagens, tanto em relação à origem quanto ao destino da viagem aérea; e) hábitos das pessoas que se utilizam do aeroporto, turistas chegando, partindo, ou em trânsito, bem como funcionários, terceirizados, visitantes, e assim por diante; f) poder aquisitivo: estes últimos recebendo a interferência de fatores, sobretudo externos, ligados à oferta e demanda por transporte aéreo, que pressupõem utilização da infraestrutura aeroportuária por públicos, com perfis distintos e cambiantes, ao longo do tempo; g) tipo de equipamento de coleta de resíduos; h) segregação na origem, quer em aeronaves, quer em aeroportos; i) sistematização da origem; j) disciplina e controle dos pontos produtores; $k$ ) leis e regulamentações específicas: voltando-se, especialmente, ao sistema de gestão ambiental, ao Plano de Gerenciamento de 
Resíduos Sólidos, ao Programa de Educação Ambiental e à legislação específica e aplicável ao gerenciamento de resíduos do aeroporto e I) a tecnologia em termos da disponibilidade de equipamentos de auxílio à navegação aérea, uma vez que condições climáticas adversas causam cancelamentos/redirecionamento de voos, o que tende a favorecer a redução da movimentação de determinados aeroportos e, por via de consequência, a geração de resíduos sólidos. Reitera-se, desse modo, a complexidade que envolve a geração e a gestão de resíduos nos empreendimentos aeroportuários.

Da razão entre a massa total de resíduos gerados em um voo e a quantidade de passageiros desembarcados depreende-se a produção desses resíduos por passageiro. Em virtude dos elementos apontados anteriormente, os passageiros da companhia aérea $A$, que se destinaram a Caxias do Sul, no período amostrado, geraram/descartaram, em média, em torno $60 \mathrm{~g}$ de resíduo durante a viagem, que costuma durar em torno de $1 \mathrm{~h} 30 \mathrm{~min}$. Essa produção é cerca de três vezes superior à geração por passageiro da companhia B: $20 \mathrm{~g} /$ passageiro/viagem. Convém assinalar que a companhia ofertava um lanche de bordo simples somente aos passageiros de um dos voos, que durava mais que $1 \mathrm{~h} 30 \mathrm{~min}$. Essa política visa, declaradamente, a evitar custos operacionais por passageiro e, dessa forma, assegurar lucratividade da empresa custo.

Na semana amostrada em agosto observou-se uma produção per capita de resíduos sólidos no sítio aeroportuário superior aos demais períodos amostrados: $50 \mathrm{~g} / \mathrm{pessoa} / \mathrm{dia}$, contra 30g/pessoa/dia na semana anterior e 40g/pessoa/dia na semana posterior, em números aproximados. Apesar de a etapa do mês de julho ter coincidido com as férias, registrou-se, no mês de agosto uma produção per capita de resíduos superior no sítio aeroportuário, seguindo a tendência dos números da geração de resíduos em aeronaves, havendo, inclusive, valores de produção per capita coincidentes. Essa produção per capita (40g/pessoa/dia) também destoa dos valores encontrados em outras pesquisas.

Explicitam-se, por meio do Quadro 1, os principais exemplos de componentes de resíduos encontrados durante a coleta de dados.

Na Tabela 2 explicitam-se os dados de composição gravimétrica, tendo por base as amostragens realizadas nos meses de agosto e outubro, quando houve caracterização dos resíduos para determinação da composição gravimétrica dos mesmos. Os números incluem dados setorizados por companhia aérea, tendo critério, também, a classificação das fontes geradoras em aeronaves e sítio aeroportuário. 
Quadro 1 - Exemplos de componentes de resíduos

\section{Grupos de componentes}

Matéria orgânica putrescível

Plástico

Papel e papelão

Vidro

Metal ferroso

Metal não ferroso

Madeira

Pano, trapo, couro e borracha

Contaminantes biológicos

Contaminantes químicos

Pedra, terra e cerâmica

Misto

Diverso

\section{Exemplos básicos de componentes}

Pó de café, cascas de fruta, pinhões e suas cascas, guardanapos sujos, biscoitos, restos de sanduíche e outros lanches, pequenas embalagens de molho e margarina (abertas ou intocadas), embalagens fechadas com biscoito e restos alimentares diversos.

Copos de bebidas, copos de isopor; embalagens de alimentos diversos (iogurte, cereal, biscoito, balas, etc.), bandejas de plástico e isopor, garrafas PET de refrigerante e água (algumas com líquido em seu interior), talheres plásticos, canudinhos, tampas de garrafa, plástico bolha, sacolas, sacos para indisposição alimentar, embalagem bag de suco, pedaços de isopor, alças e rodinhas de mala, vassoura, pedaços de canos pretos, rolos de bobina para impressora e fitas adesivas (parte destacada).

Fitas de identificação, jornais, revistas, caixas e embalagens de papelão diversas, caixas de ovos e outros alimentos, papel ofício, cartões de embarque, material de divulgação distribuído em feira, sacolas de papelão, notas e plano de vôo.

Garrafas de bebidas alcoólicas (cerveja e vinho, algumas com líquido) e de refrigerantes.

Latas de alimentos, fechos e tampas de garrafa.

Latinhas de refrigerantes e sucos (alumínio), armação de guarda-chuva, embalagem de desodorante em alumínio.

Capas de assento de aeronaves em TNT, peças de vestuário, panos de limpeza.

Papel higiênico, toalhas de papel e fraldas.

Pequenas lâmpadas fluorescentes queimadas, latas de tinta, sabonete, comprimidos e medicamentos em geral, óleo lubrificante multiviscoso.

Restos da limpeza de área verde (folhas, galhos e pedras).

Embalagens longa vida de suco, leite e creme de leite, fones de ouvido (alguns ainda embalados), embalagens aluminizadas de café a vácuo, mala, cintos de mala, fitas adesivas (etiquetas) e material elétrico.

Protetor auricular, capas de óculos, luvas, papel carbono, manta absorvente.

Fonte: Elaboração própria dos autores (2012) 
Tabela 2 - Composição gravimétrica dos resíduos sólidos aeroportuários gerados durantes as amostragens de agosto e outubro

\begin{tabular}{|c|c|c|c|c|c|c|c|c|c|c|}
\hline \multirow[t]{2}{*}{ CATEGORIA } & \multicolumn{2}{|c|}{$\begin{array}{c}\text { COMPANHIA } \\
\text { AÉREA A }\end{array}$} & \multicolumn{2}{|c|}{$\begin{array}{c}\text { COMPANHIA } \\
\text { AÉREA B }\end{array}$} & \multicolumn{2}{|c|}{ AERONAVES } & \multicolumn{2}{|c|}{$\begin{array}{c}\text { SÍTIO } \\
\text { AEROPORTUÁRIO }\end{array}$} & \multicolumn{2}{|c|}{ TOTAL } \\
\hline & $\begin{array}{l}\text { MASSA } \\
(\mathrm{kg})\end{array}$ & $\%$ & $\begin{array}{l}\text { MASSA } \\
\text { (kg) }\end{array}$ & $\%$ & $\begin{array}{c}\text { MASSA } \\
(\mathrm{kg})\end{array}$ & $\%$ & $\begin{array}{l}\text { MASSA } \\
(\mathrm{kg})\end{array}$ & $\%$ & $\begin{array}{l}\text { MASSA } \\
\text { (kg) }\end{array}$ & $\%$ \\
\hline $\begin{array}{ll}\text { Matéria } & \text { orgânica } \\
\text { putrescível } & \end{array}$ & 25,98 & 28,05 & 27,83 & 32,66 & 53,81 & 30,26 & 111,00 & 25,88 & 164,81 & 27,16 \\
\hline Plástico & 39,01 & 42,11 & 35,50 & 41,67 & 74,51 & 41,90 & 41,73 & 9,73 & 116,24 & 19,15 \\
\hline Papel e papelão & 4,44 & 4,79 & 13,40 & 15,72 & 17,84 & 10,03 & 67,33 & 15,70 & 85,17 & 14,04 \\
\hline Vidro & - & - & - & - & - & - & 19,03 & 4,43 & 19,03 & 3,14 \\
\hline Metal ferroso & - & - & 0,02 & 0,02 & 0,02 & 0,01 & 0,18 & 0,04 & 0,20 & 0,03 \\
\hline Metal não ferroso & 1,89 & 2,04 & 0,92 & 1,08 & 2,81 & 1,58 & 1,41 & 0,33 & 4,22 & 0,70 \\
\hline Madeira & - & - & - & - & - & - & - & - & - & - \\
\hline $\begin{array}{l}\text { Pano, trapo, couro e } \\
\text { borracha }\end{array}$ & 2,10 & 2,27 & 1,64 & 1,93 & 3,74 & 2,10 & 1,43 & 0,33 & 5,17 & 0,85 \\
\hline $\begin{array}{l}\text { Contaminante } \\
\text { biológico }\end{array}$ & 0,59 & 0,64 & 0,31 & 0,36 & 0,90 & 0,51 & 178,39 & 41,58 & 179,29 & 29,54 \\
\hline $\begin{array}{l}\text { Contaminante } \\
\text { químico }\end{array}$ & - & - & 0,02 & 0,02 & 0,02 & 0,01 & 1,07 & 0,25 & 1,09 & 0,18 \\
\hline $\begin{array}{ll}\text { Pedra, } & \text { terra } \\
\text { cerâmica } & \end{array}$ & - & - & - & - & - & - & 1,45 & 0,34 & 1,45 & 0,24 \\
\hline Misto & 16,43 & 17,74 & 5,40 & 6,34 & 21,83 & 12,28 & 5,49 & 1,28 & 27,32 & 4,50 \\
\hline Diversos & 2,18 & 2,36 & 0,17 & 0,20 & 2,35 & 1,32 & 0,49 & 0,11 & 2,84 & 0,47 \\
\hline TOTAL & 92,62 & 100 & 85,21 & 100 & 177,83 & 100 & 429,00 & 100 & 606,83 & 100 \\
\hline
\end{tabular}

Fonte: Elaboração própria dos autores (2012)

Em primeiro lugar, ressalta-se que as frações da composição gravimétrica obtida no mês de outubro, de acordo com os dois setores, seguiram a tendência das frações obtidas no mês de agosto, com poucas diferenças entre elas. Conforme se pode visualizar na Tabela 2, no que tange aos resíduos gerados a bordo de aeronaves, os voos da companhia aérea $A$, com destino ao aeroporto de Caxias do Sul, geraram 92,62kg.

Há, relativamente, uma inversão em termos da relevância da fração do componente papel e papelão e a de resíduos mistos. Enquanto em aeronaves da companhia aérea $A$ os resíduos de papel e papelão respondem por 4,79\% do montante gerado, os da companhia $B$ geram $15,72 \%$. Quanto à categoria "misto", a composição dos voos da companhia aérea A revela o percentual de $17,74 \%$, já a dos voos da companhia B, um percentual de 6,34\%. Tal fato pode ser explicado pelos distintos serviços de bordo oferecidos pelas companhias aéreas em questão. 0 fato de a companhia aérea $B$ apresentar um percentual excedente de papel e papelão, em relação à companhia $\mathrm{A}$, deve-se, pelo menos em parte, à oferta de revistas e encartes de bordo por parte daquela companhia, alguns deles sendo descartados, no final do voo. Tal fato que não é constatado em voos da companhia $A$, cujos resíduos compostos de papel e papelão são, em geral, jornais e outros impressos, supostamente adquiridos e descartados pelos próprios passageiros. A companhia aérea $A$ apresenta uma fração maior de resíduos mistos que a companhia $B$, pois esta oferece a cada passageiro, em todos os seus voos, sucos em embalagens individuais, elaboradas 
com material misto (tipo longa vida). O mesmo não ocorre com a companhia aérea $B$, que oferecia sucos em apenas um dos voos com destino ao aeroporto de Caxias do Sul, porém, servidos em copos plásticos, o que faz diminuir a fração correspondente à categoria "misto".

Além disso, a expressiva quantidade de fones de ouvido descartados em aeronaves da companhia A fez elevar ainda mais o percentual de resíduo misto. Portanto, a geração da categoria "misto" é maior na companhia aérea $A$ em relação à companhia $B$, tanto em termos de números relativos quanto absolutos. Foi caracterizado um total de $606,83 \mathrm{~kg}$ de resíduos sólidos oriundos tanto das aeronaves quanto do próprio sítio aeroportuário. Desse montante, 29,54\% correspondem a contaminante biológico, tendo sido gerados $179,29 \mathrm{~kg}$ desse tipo de resíduo, apenas entre 18 e 24 de agosto e entre $1^{\circ}$ e 5 de outubro, ou seja, doze dias ao todo. Pode-se dizer que praticamente todo o resíduo categorizado como tal é oriundo do próprio sítio aeroportuário, sobretudo dos sanitários do terminal de passageiros.

Há componentes cujas frações cabem ser mencionadas. Hierarquicamente, logo após o contaminante biológico aparece a matéria orgânica putrescível. Geraram-se, em doze dias amostrados, $164,81 \mathrm{~kg}$ dessa categoria de resíduo, o que corresponde a uma fração de $27,16 \%$. Ambos os setores "sítio aeroportuário" e "aeronaves" contribuíram para a geração de matéria orgânica putrescível. Contudo, comparativamente às aeronaves, o sítio aeroportuário produziu mais que o dobro desse tipo de resíduo, em números absolutos. Cabe destacar, também, as seguintes categorias de resíduos e suas frações correspondentes: plástico (19,15\%), papel e papelão $(14,04 \%)$, misto $(4,50 \%)$ e vidro $(3,14 \%)$. O plástico foi gerado, em maior quantidade, nas aeronaves. Ocorreu a geração de resíduos de papel e papelão tanto em aeronaves quanto no sítio aeroportuário. O resíduo misto teve como principal fonte geradora as aeronaves. $\mathrm{O}$ contrário ocorreu com a categoria vidro: todo o resíduo desse tipo foi gerado no sítio aeroportuário.

Houve alguns componentes de resíduos mais característicos do sítio aeroportuário (resíduos do sanitário, cartões de embarque, caixas de papelão, etc.). Outros, mais característicos das aeronaves (fones de ouvido, embalagens longa vida de suco individual, capas de assento de aeronave em TNT, etc.). Assim, cada setor gera distintos tipos de resíduos, apresentando, consequentemente, composições gravimétricas distintas. A heterogeneidade é considerável, principalmente nos resíduos do sítio aeroportuário.

\section{CONSIDERAÇÕES FINAIS}

Por meio da determinação da composição gravimétrica dos resíduos e a realização sistemática de observações diretas no aeroporto, foi possível ter a dimensão da geração dos resíduos gerados no âmbito do sítio aeroportuário e das aeronaves que se dirigem ao aeroporto. Além disso, foi possível entender as principais características e especificidades dos mesmos, bem como as condições de manejo como um todo. A partir desse diagnóstico, que sempre pode ser revisto e aprofundado, poderá haver uma intervenção em termos de gestão e gerenciamento de resíduos, com maiores chances de ser bem-sucedida. 
Torna-se necessário, pela Política Nacional de Resíduos Sólidos (Lei n. 12.305, 2010), que o empreendimento aeroportuário em questão elabore e execute seu plano de gerenciamento de resíduos, sendo que os dados levantados poderão nortear tal plano e subsidiar algumas ações, como a construção de um abrigo provisório fechado para resíduos em substituição ao sistema de conteinerização adotado.

Os números apresentados apontam, ainda, que a preocupação, por conta da necessidade de não geração e/ou redução de determinados grupos de resíduos nas aeronaves, recai sobre distintos componentes no sítio aeroportuário. Por exemplo, enquanto se poderia dar especial atenção ao plástico em possíveis campanhas de redução na geração de resíduos em aeronaves, haveria que se atentar, em se tratando do sítio aeroportuário, na segregação dos diferentes componentes, evitando a mistura com contaminante biológico (principalmente gerado nos sanitários), a fim de garantir, sobretudo, o aproveitamento dos materiais potencialmente recicláveis e o melhor manejo e disposição final dos rejeitos (papel higiênico, fraldas descartáveis, entre outros).

Assim, diante das (in)certezas referentes à geração e gestão de resíduos sólidos aeroportuários, da interveniência do turismo nesses aspectos, e da atual insuficiência na produção de conhecimento técnico-científico em torno dessa temática, questionar-se-ia, entre outros elementos: Em terminais de que modal de transporte há uma maior geração de resíduos per capita? Qual a evolução que se pode esperar na movimentação dos aeroportos de diferentes portes no País? É possível minimizar a geração de resíduos nos aeroportos, mesmo com o aumento da demanda turística que opta pelo transporte aéreo? Qual o modelo de gestão e gerenciamento de resíduos sólidos mais adequado aos aeroportos de pequeno e médio porte no País? Qual a proporção exata dos impactos ambientais decorrentes da geração de resíduos sólidos nos aeroportos do Brasil? Como as companhias aéreas, em conjunto com as autoridades aeroportuárias, trade turístico e os próprios consumidores dos serviços de transporte aéreo (passageiros/turistas) podem formular e executar ações efetivas de redução, reutilização e reciclagem dos resíduos que eles próprios colaboram para gerar?

Tais questionamentos encaminham para a necessidade de novas e constantes pesquisas acerca da temática, a fim de evitar o descompasso entre as necessidades do turismo, transporte aéreo e desenvolvimento sustentáveis, a geração de dados técnicos e a produção do conhecimento científico propriamente ditos. A produção do conhecimento é um meio que visa a um fim maior, o desenvolvimento sustentável e que inclua, portanto, a manutenção e melhoria da qualidade de vida das populações, o que envolve, entre outros elementos, a proteção ambiental.

\section{AGRADECIMENTOS}

Os autores agradecem ao Aeroporto Hugo Cantergiani; a CAPES e ao CNPq. 


\section{REFERÊNCIAS}

Associação Brasileira de Normas Técnicas (2005). NBR 14004: Sistemas de gestão ambiental - Diretrizes gerais sobre princípios, sistemas e técnicas de apoio. Rio de Janeiro: ABNT.

Associação Brasileira de Normas Técnicas. (1996). NBR 8.843: Resíduos sólidos de aeroportos gerenciamento. Rio de Janeiro: ABNT.

Atkin, P.; Hershkowit, A.; Hoover, D. (2006). How airlines and airports can clean up their recycling programs. Nova York: NRDC.

Ayuso, M. J. S. M. (2002). Turismo y desarollo sostenible. In J. Aliseda \& S. Jaquenod (Orgs.). Ambiente y desarollo sostenible. Cáceres, Espanha: Servicio de Publicaciones de la Universidad de Extremadura.

Beni, M. C. (2007). Análise estrutural do turismo. (12ª ed). São Paulo: Senac São Paulo.

Blázquez, J. G. (2002). El desarollo de la normativa en el transporte aéreo. In J. Aliseda \& S. Jaquenod (Orgs.). Ambiente y desarollo sostenible. Cáceres, Espanha: Servicio de Publicaciones de la Universidad de Extremadura.

Cooper, C., Fletcher, J., Fyall, A. G., \& Bent, D. (2007). Turismo: princípios e práticas. (3 $3^{\mathrm{a}}$ ed). Porto Alegre: Bookman.

De Conto, S. M., Silva, E. J. A., \& Pessin, N. (2005). Gestão de resíduos sólidos em um meio de hospedagem: um estudo de caso. Anais do Congresso Brasileiro de Ciência e Tecnologia em Resíduos Sólidos e Desenvolvimento Sustentável, Florianópolis, SC, Brasil, 1.

De Conto, S. M., Pessin, N., Pistorello, J., Zaro, M. \& Poletto, M. (2009). Geração de resíduos sólidos em um meio de hospedagem da Região da Uva e Vinho no Estado do Rio Grande do Sul. Anais do Congresso Brasileiro de Engenharia Sanitária e Ambiental - ABES, Recife, PE, Brasil, 25.

Gonçalves, E. dos S. (2009). Externalidades aeroportuárias e aeronáuticas: uma aproximação aos impactos econômico, ambiental, espacial e sócio-cultural. Dissertação de mestrado, Centro Universitário Franciscano do Paraná, Curitiba, PR, Brasil.

Hatem, R. S. (2003). Avaliação dos resíduos sólidos gerados nos principais aeroportos da região metropolitana de Belo Horizonte-MG. Dissertação de mestrado, Universidade Federal de Minas Gerais, Belo Horizonte, MG, Brasil.

Kunz, J. G.; De Conto, S. M. (2011). O turismo brasileiro e a relevância da gestão ambiental em terminais aeroportuários. Anais do Seminário da Associação Nacional de Pesquisa e Pós-Graduação em Turismo ANPTUR, Balneário Camboriú, SC, Brasil, 8.

Kunz, J. G.; De Conto, S. M. (2012). A geração de resíduos sólidos aeroportuários e o turismo ambientalmente sustentável. Anais do Congresso Internacional de Tecnologia para o Meio Ambiente, Bento Gonçalves, RS, Brasil, 3. 
Kunz, J. G.; De Conto, S. M.; Denicol, M. S. G. M. (2012). O Turismo e a produção científica sobre transporte aéreo na pós-graduação stricto sensu brasileira. Anais do Seminário da Associação Nacional de Pesquisa e Pós-Graduação em Turismo - ANPTUR, São Paulo, SP, Brasil, 9.

Lei n. 12.305, de 02 de agosto de 2010 (2010). Institui a Política Nacional de Resíduos Sólidos; altera a Lei no 9.605, de 12 de fevereiro de 1998; e dá outras providências. Brasília. 2010. Disponível em: <http://www.planalto.gov.br/ccivil_03/_ato2007-2010/2010/lei/l12305.htm> [25 maio 2012].

Lima, L. M. Q. (2002). Biorremediação de lixões - Aplicações da Biotecnologia. Campinas: Editora da Unicamp.

Mandelli, S. M. de C. (1997). Variáveis que interferem no comportamento da população urbana no manejo de resíduos sólidos domésticos no âmbito das residências. Tese de doutorado, Universidade Federal de São Carlos, São Carlos, SP, Brasil.

Mandelli, S. M. de C., Zattera, A. J., Carvalho, G. A. \& Matté, L. L. Composição gravimétrica de resíduos sólidos domésticos - um estudo de caso. Anais do Seminário Nacional de Resíduos Sólidos, Gramado, RS, Brasil, 6.

Monteiro, J. H. P. et al. (2001). Manual de gerenciamento integrado de resíduos sólidos. Rio de Janeiro: IBAM.

Palhares, G. L. (2000). Transporte aéreo e turismo: gerando desenvolvimento socioeconômico. São Paulo: Aleph.

Peeters, P., Szimba, E., \& Duijnisved, M. (2007). Major environmental impacts of European tourist transport. Journal of Transport Geography, 15(2), 83-93.

Pitt, M. \& Smith, A. (2003). Waste management efficiency at UK airports. Journal of Air Transport Management, 9(2), 103-111.

Sachs, I. (2002). Caminhos para o desenvolvimento sustentável. (2 ${ }^{\mathrm{a}}$ ed). Rio de Janeiro, Garamond.

Schneider, S. C. R. F. (2004). Gerenciamento de resíduos sólidos em aeroportos: estudo de caso Aeroporto Internacional Salgado Filho. Dissertação de mestrado, Universidade Federal de Santa Catarina, Florianópolis, SC, Brasil. Disponível em: http://www.tede.ufsc.br/teses/PGEA0242.pdf [09 fev. 2012].

Ventura, K. S. (2012). Diagnóstico dos resíduos sólidos de transportes aéreos e aquaviários - Relatório de Pesquisa. Brasília: IPEA. Disponível em: http://www.ipea.gov.br/agencia/images/stories/PDFs/relatoriopesquisa/121009_relatorio_transportes_ae reos.pdf [10 fev. 2013].

X, D. Li, C. S. Poon, S. C. Lee, S. S. Chunga e F. Luk. (2003). Waste reduction and recycling strategies for the in-flight services in the airline industry. Resources, Conservation and Recycling, 37(2), 87-99.

Artigo recebido em: 10/03/2014.

Artigo aprovado em: 15/04/2015. 